\title{
ANÁLISE DAS CONDIÇÕES DO CONCRETO DO CANAL DE RETENÇÃO DE AREIA DE UMA ESTAÇÃO DE PRÉ-CONDICIONAMENTO DE ESGOTO
}

\author{
BEZERRA, JOSÉ EMIDIO ALEXANDRINO \\ Profissão Prof. Me, Engo . Civil \\ Instituição Universidade de Fortaleza \\ Estado; País Ceará; Brasil \\ e-mail joseemidiobezerra@outlook.com
}

\author{
CABRAL, ANTÔNIO EDUARDO BEZERRA \\ Profissão Prof. Dr. Eng ${ }^{\circ}$. Civil \\ Instituição Universidade Federal do Ceará \\ Estado; País Ceará; Brasil \\ e-mail eduardo.cabral@ufc.com
}

\author{
LIMA, ANDRÉLIA DE FREITAS \\ Profissão Enga . Civil \\ Instituição Universidade de Fortaleza \\ Estado; País Ceará; Brasil \\ e-mail andreliafreitas@gmail.com
}

\author{
OSHIRO, ANGEL \\ Profissão Prof. Ing. \\ Instituição universidad Tecnologica Nacional \\ Estado; País Argentina \\ e-mail oshiroangel@gmail.com
}

\section{RESUMO}

Este trabalho apresenta um estudo sobre as condições do concreto nas paredes de uma célula desarenadora em uma Estação de Pré-Condicionamento de Esgoto com a finalidade de determinar a necessidade e a extensão de reparos estruturais. A estrutura analisada está inserida em um ambiente de alta agressividade, requerendo dessa forma, um monitoramento das condições do concreto. A análise foi realizada a partir de ensaios não destrutivos com o intuito de avaliar a dureza superficial do concreto, a frente de carbonatação e profundidade de penetração de cloretos na estrutura. Os resultados obtidos no ensaio de carbonatação apontam que nos locais não submersos a frente de carbonatação apresentou uma penetração de $1,5 \mathrm{~cm}$ do cobrimento da estrutura e nos pontos situados na zona submersa, a carbonatação alcança $0,5 \mathrm{~cm}$. A resistência a compressão em 04 dos 06 pontos estudados estão em conformidade com o Fck estabelecido em projeto. $O$ ensaio de determinação de cloretos identificou que a penetração de cloretos foi de $0,5 \mathrm{~cm}$ não atingindo a armadura, embora a estrutura esteja muito próxima do mar.

Palavras-chave: Concreto. Ensaios de Carbonatação. Cloretos. Ambiente.

\section{ABSTRACT}

This work presents a study on the condition of the concrete in the walls of a sandessless cell in a sewage preconditioning station in order to determine the need and extent of structural repairs. The structure analyzed is inserted in an environment of high aggressiveness, requiring this way, a monitoring of the conditions of the concrete. The analysis was performed from non destructive tests to evaluate the surface hardness of the concrete, the carbonation front and the depth of chloride penetration in the structure. The results obtained in the carbonation test show that in the non-submerged places the carbonation front had a penetration of $1.5 \mathrm{~cm}$ of the structure covering and in the points in the submerged zone, the carbonation was $0.5 \mathrm{~cm}$. The compressive strength in 04 of the 06 studied points are in accordance with the established Fck in design. The chloride determination test found that chloride penetrated $1.5 \mathrm{~cm}$ and did not reach the reinforcement although the structure is very close to the sea.

Keywords: Concrete. Carbonation assay. Chlorides. Environment.

\section{PATOLOGIAS DAS ESTRUTURAS DE CONCRETO ARMADO EM AMBIENTES AGRESSIVOS}

De acordo com a ISO 13823 (AMERICAN CONCRETE INSTITUTE, 2008), durabilidade é a capacidade de uma estrutura ou de seus componentes de satisfazer, com dada manutenção planejada, os requisitos de desempenho do projeto por um período específico de tempo sob influências das ações ambientais, ou como resultado do processo de envelhecimento natural.

A durabilidade, portanto, pode estar relacionada com a interação entre a estrutura de concreto, o ambiente e as condições de utilização e manutenção. Não sendo considerado propriedade especifica da estrutura, da armadura ou do concreto, ou seja, a mesma estrutura pode ter diferentes comportamentos ao longo do tempo. (MEDEIROS; ANDRADE E HELENE 2011). 
O conceito de durabilidade pode ser confundido com o de vida útil. A NBR 6118, (ABNT, 2014), define vida útil, como sendo o período de tempo no qual se mantém as características das estruturas de concreto. Para que isso ocorra devem ser atendidos os requisitos de uso e manutenção recomendadas, assim como de execução dos reparos decorrentes de danos acidentais. Desta forma, a vida útil pode ver vista como característica temporal, que consiste em calcular a estimativa de duração de uma determinada estrutura.

\subsection{Deterioração do concreto}

Pinheiro e Brandão (1999) abordam a deterioração como um termo com sentido oposto ao de durabilidade, que é definida como a capacidade de um determinado material de suportar as condições para as quais foi projetado, sem perdas significativas ao longo de um determinado período.

A deterioração das estruturas pode ocorrer devido ao envelhecimento natural, acidentes, má escolha dos materiais e falhas na execução da obra. (SOUZA e RIPPER 1998). O envelhecimento da edificação é um fenômeno natural, no entanto, pode gerar preocupação caso o processo de deterioração se desenvolva mais rápido do que o previsto, desse modo, a estrutura poderá necessitar de alguma forma de intervenção para cumprir a vida útil esperada.

As causas de deterioração, portanto, podem ter origem devido as ações químicas, físicas ou biológicas, podendo ocorrer de forma isolada ou conjunta. Os efeitos dessas ações têm relação direta com o meio a qual a estrutura está exposta. (ANDRADE \& SILVA, 2005).

O meio ao qual a estrutura está inserida tem grandes impactos sobre a deterioração do concreto. De acordo com a NBR 6118 (ABNT, 2014) a agressividade do meio ambiente está relacionada às ações físicas e químicas que atuam sobre as estruturas de concreto.

O meio ambiente marinho é um dos que mais afetam as estruturas de concreto, pois devido a elevada presença de cloretos na presença de água pode ser fator determinante para desencadear o processo de corrosão das armaduras. Também as estruturas expostas ao esgoto sofrem severos ataques, pois estão sujeitas à agressão tanto pelas bactérias presentes no esgoto, como devido a reação do enxofre com cimento, o que resulta na degradação do concreto (GONÇALVES, 2015).

Determinadas substâncias encontradas no meio ambiente podem penetrar nas estruturas de concreto, através estrutura porosa do concreto, que quando são submetidas a condições favoráveis de umidade e temperatura podem provocar reações químicas e consequentemente danos.

\subsubsection{Ações químicas}

De modo geral, o concreto, possui baixa resistência à degradação devido por processos químicos, tornando-se vulnerável a esse tipo de ataque que possui grande influência no que se refere a deterioração das estruturas (BRANDÃO,1998).

A presença de água é o principal fator de mecanismo de transporte, e que pode ocasionar diversos tipos de deterioração. O processo químico de degradação depende da estrutura interna da pasta, da concentração de agentes químicos e do processo de transporte de substâncias. Deste modo, para que seja evitado o tal processo é fundamental controlar a natureza e distribuição dos poros e das fissuras, assim um controle na fase de execução, principalmente quanto ao lançamento, adensamento e cura do concreto (SILVA, 2015).

\subsubsection{Ataque por água do mar}

De acordo com Souza e Ripper (1998) a água do mar, aliada aos movimentos e os choques das ondas, bem como os ciclos alternados de molhagem e secagem, devido ao fenômeno das marés, tendem a provocar graves agressões as estruturas de concreto. Essa ação se dá principalmente pela água salgada conter cloretos e sulfatos de sódio e magnésio, em sua composição e são substâncias bastante agressivas.

As presenças desses sais em elevadas concentrações podem provocar a deterioração do concreto, sobretudo em regiões de clima quente, onde os efeitos dos ataques são mais severos. (BRANDÃO, 1998).

Por conta da presença de sulfato na água do mar, há algumas vezes a indicação equivocada referente ao uso de cimentos com alta resistência a sulfatos em ambientes marítimos, no entanto, é importante se atentar ao fato, que esse tipo de 
cimento possui maior permeabilidade a ação dos cloretos, e estes estão presentes na água do mar em elevada concentração. $\mathrm{O}$ ingresso dos cloretos na estrutura leva à corrosão das armaduras, Processo que é considerado mais severo que o ataque potencial devido aos íons de sulfato (HELENE, 2003).

De acordo com Brandão (1998) a presença dos cloretos altera a dimensão e a natureza das reações químicas, diminuindo os efeitos dos ataques por sulfatos, os quais tornam-se secundários na presença de cloretos. Desse modo, a água do mar é considerada apenas como moderadamente agressiva em relação ao sulfato, e altamente agressiva em relação aos cloretos.

\subsubsection{Ataque por ácidos}

Segundo Brandão (1998) os ácidos, orgânicos ou inorgânicos, são responsáveis pela deterioração nas estruturas de concreto armado devido à reação química que ele provoca ao entrar em contato com os compostos de cálcio presente no cimento como os silicatos, aluminatos e hidróxido de cálcio. Esses componentes são transformados em sais de cálcio solúveis em água, os quais podem ser lixiviados e consequentemente perdem a capacidade de ligação entre os componentes do concreto.

Os ácidos causam danos ao concreto agindo sobre a superfície porosa do mesmo e produzindo uma modificação em sua composição. Resultando na deterioração a partir redução da área de seção do concreto, iniciando pela superfície exposta. A velocidade da degradação é depende concentração e quantidade do ácido que ao qual o concreto está exposto. (ANDRADE; et al., 2003).

Para Helene (2003), o ataque causado por ácidos provoca a desintegração da pasta de cimento, tornando a estrutura vulnerável uma vez que os agregados ficam expostos, além de ocasionar a redução da alcalinidade e a consequentemente a perda de passivação das armaduras, ficando assim expostas a fenômenos corrosivos.

Em ambientes com alto teor de sulfetos, como o caso das estações de tratamento de esgoto, e comum observar a despassivação da armadura por ataque ácido, que ocorre após a expansão do concreto e a perda do cobrimento, provocando a corrosão da armadura devido a ação das bactérias e do ácido sulfúrico (MAIA e D’ÁVILA, 2007)

\subsection{Ataque por Cloretos}

De acordo com Souza e Ripper (1998), os cloretos podem ser adicionados ao concreto espontaneamente, essa, adição pode ocorrer a partir do uso de aditivos aceleradores de pega, de águas e agregados contaminados e podem penetrar no concreto através de sua superfície porosa.

Segundo Perdrix (1992) os cloretos podem ser encontrados dentro dos concretos de duas formas, como cloretos livres ou combinados. O primeiro se apresenta na forma de íons inseridos água dos poros, e são considerados realmente perigosos e agressivos a armadura, já os cloretos combinados se apresenta na fase hidratada do cimento associado na forma de cloroaluminatos. A soma dessas duas formas resulta no cloreto total. O cloreto livre é de fácil extração enquanto o cloreto os combinados são incorporados pelas paredes dos poros.

O elevado teor de Íon Cloro (Cloreto) tem como consequência a despassivação da armadura. O processo se dá pela penetração do cloreto através dos poros do concreto ou trincas, por difusão, impregnação ou absorção capilar. Quando a quantidade de cloreto supera um certo limite de concentração em relação a de hidroxilas nos poros do concreto, ocorre a despassivação da superfície do aço, iniciando o processo de corrosão.

Segundo a NBR 6118 (ABNT, 2014) A despassivação pela ação de cloretos, ocorre devido ao rompimento pontual da camada de passivação, esse fenômeno ocorre em função do elevado teor de íon-cloro. $\mathrm{O} \mathrm{Cl}^{-}$em contato com o íon ferro presente no aço reage e forma, cloreto ferroso (extremamente instável).

Ações como maior cobrimento das armaduras e controle da fissuração podem minimizar este efeito, assim como o uso de um concreto de pequena porosidade ou utilização de cimento composto com adição de escória ou material pozolânico.

\subsubsection{Cristalização dos sais}

A deterioração devido a cristalização dos sais é comum aos ambientes marinhos, onde a água salina ao penetrar num concreto com elevada permeabilidade, numa superfície exposta ao ar, após a evaporação da água, deixa os sais no 
concreto, que sendo higroscópico, aumentam de volume e são responsáveis pelo surgimento de eflorescências e desagregação da camada superficial do concreto. Recomenda-se o uso de concretos menos porosos e de baixa permeabilidade para prevenção deste tipo de deterioração (BRANDÃO, 1998).

\subsubsection{Ataque por dióxido de carbono}

O dióxido de carbono $\left(\mathrm{CO}_{2}\right)$, ou anidrido carbônico, está presente no ar atmosférico das grandes cidades e áreas industriais, dissolvido nas águas do mar e de chuvas ácidas. A transformação do hidróxido de cálcio em carbonato de cálcio reduz o pH do concreto e despassiva a armadura, deixando-a sugesta à oxidação e posterior corrosão. $\mathrm{O}$ dióxido de carbono e cloretos são os considerados os principais agentes causadores da corrosão das armaduras nas estruturas de concreto armado.

\subsubsection{Ataques por abrasão}

São diversos os agentes responsáveis pelo processo de abrasão ao concreto, dentre eles os mais comuns são o ar e a água, que são responsáveis pelo transporte de partículas que desencadeiam o fenômeno de abrasão. A ação dessas partículas carregadas pelo movimento da água e pelo ar, geralmente ocasiona a erosão. A quantidade de partículas em suspensão, assim como a forma, tamanho, dureza, velocidade e turbulência da água ou do ar, e ainda a qualidade do concreto da estrutura atacada serão fatores determinantes a severidade do ataque (SOUZA e RIPPER 1998).

De acordo com Brandão (1998), a resistência do concreto à abrasão é determinada pela capacidade de sua camada superficial resistir ao desgaste por atrito, ao longo do tempo. O processo ocorre a medida que a camada superficial do concreto é desgastada e os agregados ficam expostos, então, a resistência passa a ser função da aderência entre a pasta e os agregados e da dureza dos agregados, os quais são mais resistentes à abrasão do que a pasta de cimento. Mesmo os melhores concretos em algum momento sofrerão efeitos devido abrasão, no entanto, para minimizar os impactos recomenda-se evitar alterações no fator a/c durante a obra, adotar procedimentos de cura adequada, e evitar segregações e exsudação excessivas.

\subsubsection{Ataque por agentes biológicas}

Os processos biológicos podem ser resultado de ataques químicos de ácidos, oriundos a partir do surgimento de plantas e raízes, bem como de algas que acomodam nas fissuras ou poros do concreto ou ainda pela ação dos sulfetos presentes nos esgotos. Entre estes, destaca-se o ataque devido aos sulfetos, que dissolvidos na água inicialmente se apresenta na forma de gás sulfídrico $\left(\mathrm{H}_{2} \mathrm{~S}\right)$. Na presença de bactérias aeróbias o $\mathrm{H}_{2} \mathrm{~S}$ reage com o cálcio presente no cimento, formando o sulfureto de cálcio, ocasionando o fenômeno de descalcificação do concreto e consequentemente o amolecimento da pasta de cimento (SOUZA e RIPPER 1998).

Para Brandão (1998) os locais onde há a presença de esgoto, são os mais propícios aos ataques biológicos, devido a uma elevada quantidades de nutrientes pode ocorrer a proliferação de parasitas, tais como algas, moluscos e outros organismos microscópicos, ocasionando o aumento do grau de saturação nas regiões afetadas, devido à retenção de maior quantidade de água. As penetrações desses organismos são responsáveis pelo surgimento de fissuras no concreto propiciando que deteriorações mais severas de instalem.

A região submersa em contato com o esgoto não sofre com ação dos agentes agressores, porém a deterioração das estruturas ocorre sobre a linha d'água, deixando o concreto mais frágil comprometendo sua vida útil e durabilidade (SILVA, 2015).

\section{METODOLOGIA}

A metodologia utilizada para a realização deste trabalho iniciou-se com uma pesquisa bibliográfica em livros, trabalhos científicos e normas técnicas referentes ao tema estudado. Em seguida foram realizadas visitas técnicas à Estação de Pré Condicionamento de Esgoto para levantamentos de dados, registros fotográficos, coleta de amostras e realização dos ensaios através de métodos não destrutivos. Desses métodos, foram estabelecidos para o estudo, os ensaios de esclerometria, determinação de cloretos e carbonatação. 


\subsection{Ensaios in loco e laboratoriais}

O desarenador da ETE tem 04 (quatro) células e foi escolhida para realização dos ensaios a célula $\mathrm{N}^{\circ} 02$. A célula é do tipo canal aerado e possui as seguintes características dimensionais: comprimento de $18,00 \mathrm{~m}$, largura de $6,00 \mathrm{~m}$ e altura de 5,00 m. Nela foram realizados os ensaios não destrutivos para análise das condições do concreto, através dos ensaios de esclerometria, profundidade de carbonatação e determinação de cloretos. Ver a Figura 1.

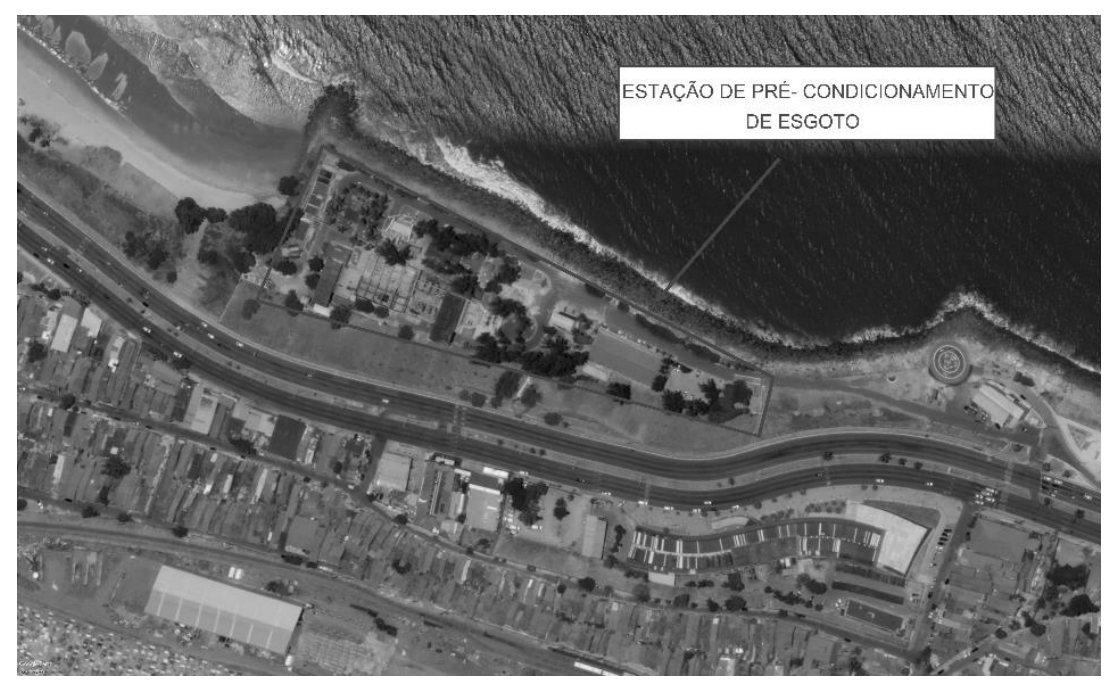

Figura 1: Localização da área de estudo

Considerando que as caixas de areia possuem formato retangular, foram escolhidas a face esquerda e do fundo para realização dos testes. Em cada parede foram analisados 03 pontos, distribuídos nas alturas de 1,00 m, 2,00 m e 4,10 m, conforme Figura 2.

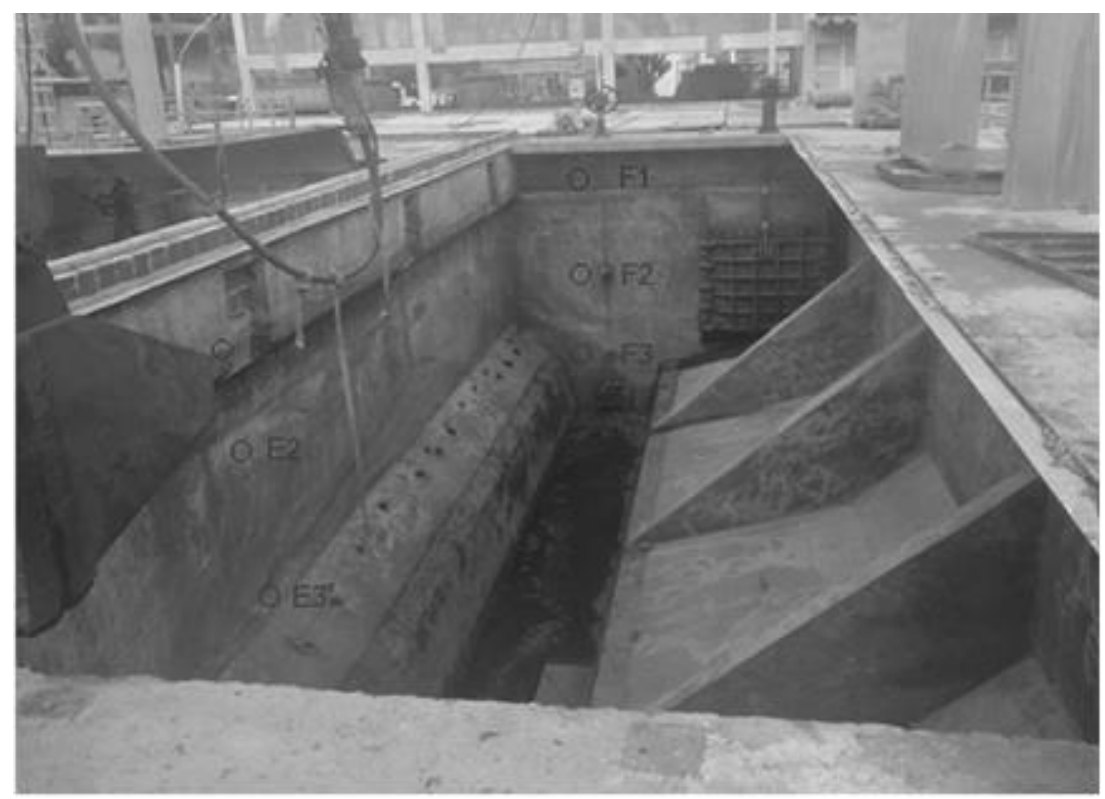

Figura 2: Célula desarenadora

\subsubsection{Resistência à compressão por esclerometria}

Neste ensaio, verifica-se a resistência à compressão e a homogeneidade do concreto através da sua dureza superficial. Foi utilizado para realização do ensaio o esclerômetro de reflexão. O princípio do equipamento consiste fundamentalmente em uma massa martelo lançada contra a superfície através de uma mola que se choca por meio de uma haste com ponta em formato esférico na área a ser ensaiada. Parte da energia do impacto é utilizada na deformação permanente e outra parte conservada elasticamente, propiciando o retorno do martelo ao fim do impacto. Quanto maior a dureza da superfície 
ensaiada, menor a parcela da energia que se converte em deformação permanente, ou seja, maior deve ser o recuo do martelo. NBR 7584, (ABNT, 2012).

Nesse contexto, para análise da resistência à compressão dos locais indicados, limpou-se a superfície desses com uma lixa e definiu-se a malha com 09 quadrantes, $3 \mathrm{~cm} \mathrm{x} 3 \mathrm{~cm}$, utilizando de giz de cera. Esse procedimento foi realizado nos 06 pontos escolhidos.

Em seguida, realizou-se a compressão do esclerômetro em cada um dos 09 quadrantes. Após empurrar o martelo de teste contra a superfície analisada, os dados foram exibidos na tela do aparelho e anotados.

Com os índices esclerométricos individuais (IE) obtidos realizaram-se os cálculos necessários de acordo com a NBR 7584 para obtenção do índice esclerométrico efetivo de cada área, onde foram desconsiderados os valores com variação de \pm $10 \%$.

\subsubsection{Determinação de cloretos}

A análise da profundidade de penetração de cloretos em estruturas de concreto armado tem grande relevância, pois é possível avaliar a presença ou não de cloretos em diferentes camadas do concreto. Dessa forma, é possível evitar a ruptura local da camada de passivação que inibe o processo de corrosão das armaduras, podendo ocorrer pelo teor elevado do íon cloro.

As amostras foram coletadas na forma pulverulenta, com a utilização de furadeira de impacto. Foram realizados furos a cada $0,5 \mathrm{~cm}$ até atingir a profundidade $2,0 \mathrm{~cm}$ nos pontos E1 e F1 (região onde não há contato direto com o esgoto) e 1,5 $\mathrm{cm}$ nos demais pontos (zona submersa). As 20 amostras colhidas foram armazenadas em sacos plásticos e identificadas.

A determinação da concentração de cloretos foi obtida através do método de Mohr, conforme Berenguer et al. (2018). As análises foram realizadas no Laboratório de Química Tecnológica da Universidade de Fortaleza- UNIFOR.

Para preparação das soluções, foram pesados $0,5 \mathrm{~g}$ do pó (concreto) de cada amostra e colocados em beckers. Com auxílio de uma proveta, adicionou-se $50 \mathrm{~mL}$ de água destilada e homogeneizou-se. Depois de diluída, cada amostra foi transferida cuidadosamente para um balão volumétrico de $250 \mathrm{~mL}$, através de bastão e funil, completando o volume com água destilada.

Para a titulação das soluções, transferiu-se $25 \mathrm{~mL}$ com uso de pipeta volumétrica para um Erlenmeyer e adicionou-se 10 gotas de Cromato de potássio $\left(\mathrm{K}_{2} \mathrm{CrO}_{4}\right)$, indicador que se apresentou com coloração amarela. Após isso, iniciou-se a titulação com nitrato de prata $\left(\mathrm{AgNO}_{3}-0,0141 \mathrm{~mol} / \mathrm{l}\right)$. No ponto de viragem, a amostra apresentou coloração vermelhotelha (Figura 3), e imediatamente anotou-se o volume gasto, ou seja, a quantidade de $\mathrm{AgNO}_{3}$ necessária para associar-se aos íons cloretos livres de cada amostra. Ressalte-se que as amostras foram analisadas em duplicata e para evitar interferências da água destilada, realizou-se a prova em branco.

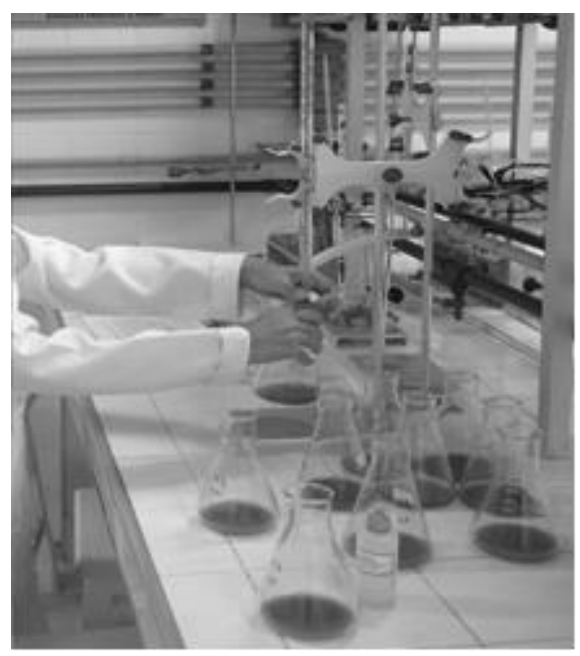

Figura 3: Armazenamento e identificação das amostras 
Para o cálculo do percentual de cloreto absorvido, foi utilizada a Equação 1 (BERENGUER et al., 2018).

$$
\frac{m g}{L} \cdot C L^{-}=\frac{(v 1-v 2) \times m \times m m \times 1000}{\text { Vamostra } \times \text { fator de diluíção }} \quad \text { (Equação 1) }
$$

Onde:

V1: volume da solução de $\mathrm{AgNO}_{3}$ gasto para titular a amostra, em ml

V2: volume de solução de $\mathrm{AgNO}_{3}$ gasto para titular o branco, em ml

M: concentração molar da solução de $\mathrm{AgNO}_{3} \mathrm{em} \mathrm{mm:}$

$m g / l \mathrm{CL}^{-}$: massa molar de $\mathrm{Cl}^{-}$

V: volume da amostra

Fator de diluição $=1000 / 250=4$

\subsubsection{Profundidade de carbonatação}

A determinação da profundidade de carbonatação foi realizada por meio de uma solução indicadora de $\mathrm{pH}$ nas proporções de $1 \%$ de fenolftaleína, $50 \%$ de álcool etílico e $50 \%$ de água destilada. Esse indicador, em contato com a região carbonatada, não altera a cor do concreto indicando um pH ácido, mas quando em contato com a região não carbonatada, a cor é alterada para vermelho carmim, ou seja, apresenta um $\mathrm{pH}$ básico. A mudança da cor ocorre no intervalo entre $\mathrm{pH}$ 8,2 e pH 9,8. Os testes realizados foram baseados nas recomendações da CPC-18 do RILEM (1998).

O ensaio foi realizado através de perfuração por etapas nas diferentes profundidades. Verificou-se a ocorrência ou não de carbonatação no local, através da aspersão da solução indicadora de fenolftaleína nas perfurações da parede em cada um dos pontos analisados e em cada profundidade. Os furos tiveram avanços de $0,5 \mathrm{~cm}$ até atingir a profundidade de $2,0 \mathrm{~cm}$ nos pontos E1 e F1 (área sem contato com esgoto) e profundidade de $1,5 \mathrm{~cm}$ nos demais pontos.

\section{RESULTADOS}

Com base nos testes realizados serão apresentados nesse item os resultados de cada ensaio. Esses dados são imprescindíveis para que seja possível fazer uma análise da situação da estrutura.

\subsection{Profundidade de Carbonatação}

A tabela 2 mostra os resultados obtidos através do teste realizado com a solução indicadora. A cor verificada em cada um dos pontos, nas diferentes profundidades está relacionada com $\mathrm{pH}$ do concreto. Quando a coloração apresenta-se incolor indica que a região está carbonatada, no entanto, a coloração vermelho-carmim indica que o pH no local é alcalino, ou seja, não carbonatada.

\begin{tabular}{|c|c|c|c|c|c|c|c|}
\hline & & & & & & & \\
\hline Ponto & Altura & Profundidade & da coloração & Resultado & Ponto & da coloração & Resultado \\
\hline \multirow{5}{*}{ E1 } & \multirow{5}{*}{4,10} & 0,5 & INCOLOR & CARBONATADO & \multirow{5}{*}{$\mathrm{F} 1$} & INCOLOR & CARBONATADO \\
\hline & & 1,0 & INCOLOR & CARBONATADO & & INCOLOR & CARBONATADO \\
\hline & & 1,5 & INCOLOR & CARBONATADO & & INCOLOR & CARBONATADO \\
\hline & & 2,0 & VER.LHO- & NÃO & & VERMELHO- & NÃO \\
\hline & & & CARMIN & CARBONATADO & & $\begin{array}{l}\text { CARMIN } \\
\text { VERMELHO- }\end{array}$ & $\begin{array}{c}\text { CARBONATADO } \\
\text { NÃO }\end{array}$ \\
\hline \multirow{3}{*}{ E2 } & \multirow{3}{*}{2,00} & 0,5 & INCOLOR & CARBONATADO & \multirow{3}{*}{ F2 } & CARMIN & CARBONATADO \\
\hline & & 1,0 & $\begin{array}{l}\text { VERMELHO- } \\
\text { CARMIN }\end{array}$ & $\begin{array}{c}\text { NÃO } \\
\text { CARBONATADO }\end{array}$ & & $\begin{array}{l}\text { VERMELHO- } \\
\text { CARMIN }\end{array}$ & $\begin{array}{c}\text { NÃO } \\
\text { CARBONATADO }\end{array}$ \\
\hline & & 1,5 & $\begin{array}{l}\text { VERMELHO- } \\
\text { CARMIN }\end{array}$ & $\begin{array}{c}\text { NÃO } \\
\text { CARBONATADO }\end{array}$ & & $\begin{array}{l}\text { VERMELHO- } \\
\text { CARMIN }\end{array}$ & $\begin{array}{c}\text { NÃO } \\
\text { CARBONATADO }\end{array}$ \\
\hline \multirow{4}{*}{ E3 } & \multirow{4}{*}{1,00} & 0,5 & INCOLOR & CARBONATADO & \multirow{4}{*}{ F3 } & $\begin{array}{l}\text { VERMELHO- } \\
\text { CARMIN }\end{array}$ & $\begin{array}{c}\text { NÃO } \\
\text { CARBONATADO }\end{array}$ \\
\hline & & & VERMELHO- & $\mathrm{NÃO}$ & & VERMELHO- & NÃO \\
\hline & & 1,0 & CARMIN & CARBONATADO & & CARMIN & CARBONATADO \\
\hline & & 1,5 & $\begin{array}{l}\text { VERMELHO- } \\
\text { CARMIN }\end{array}$ & $\begin{array}{c}\text { NÃO } \\
\text { CARBONATADO }\end{array}$ & & $\begin{array}{l}\text { VERMELHO- } \\
\text { CARMIN }\end{array}$ & $\begin{array}{c}\text { NÃO } \\
\text { CARBONATADO }\end{array}$ \\
\hline
\end{tabular}


Observou-se que os pontos (E1 e F1), que não ficam em contato direto com o esgoto, a frente de carbonatação apresentou um maior avanço atingindo $1,5 \mathrm{~cm}$ do cobrimento da estrutura. Nos demais pontos, quando ocorreu a carbonatação, foi identificada apenas na região mais superficial, ou seja $0,5 \mathrm{~cm}$.

O fato das regiões submersas apresentarem menor grau de carbonatação, pode está relacionado a dificuldade de acesso do $\mathrm{CO}_{2}$ aos poros do concreto devido à lâmina líquida do efluente.

Considerando que o cobrimento adotado em projeto é de $4,0 \mathrm{~cm}$, é possível observar que nos pontos mais críticos, $62 \%$ do cobrimento total mantém-se alcalino, sendo, desse modo, uma condição favorável a proteção da armadura.

\subsection{Ensaio de Esclerometria}

A tabela 1, apresenta as informações referentes ao ensaio de esclerometria, como os índices esclerométricos efetivos (IE, efetivos) e fck, determinados para cada área analisada.

Tabela 2-Resultado ensaio de esclerometria

\begin{tabular}{l|l|l|l|l|l|l}
\hline \multicolumn{5}{c}{ Ensaio Esclerométrico } \\
\hline \multirow{2}{*}{$\mathrm{N}^{\text {o de golpes }}$} & \multicolumn{5}{|c}{ Resistência à compressão - MPa } \\
\cline { 2 - 7 } & E1 & E2 & E3 & F1 & F2 & F3 \\
\hline 01 & 53,0 & 30,0 & 36,0 & 56,0 & 49,0 & 41,0 \\
\hline 02 & 55,5 & 35,5 & 34,0 & 62,0 & 44,5 & 44,5 \\
\hline 03 & 52,5 & 35,5 & 40,5 & 58,0 & 47,5 & 36,5 \\
\hline 04 & 55,5 & 35,0 & 41,5 & 55,0 & 50,5 & 41,0 \\
\hline 05 & 51,0 & 35,5 & 38,5 & 61,0 & 53,0 & 41,0 \\
\hline 06 & 50,0 & 35,5 & 34,0 & 59,0 & 46,5 & 42,5 \\
\hline 07 & 50,5 & 32,5 & 32,0 & 56,0 & 42,5 & 38,0 \\
\hline 08 & 51,0 & 31,0 & 32,0 & 64,0 & 52,5 & 41,0 \\
\hline 09 & 48,8 & 38,5 & 29,5 & 68,0 & 39,0 & 45,5 \\
\hline IE MÉDIO & 52,0 & 34,3 & 35,3 & 59,9 & 47,2 & 41,2 \\
\hline$+10 \%$ & 57,2 & 37,8 & 38,9 & 65,9 & 51,9 & 45,3 \\
\hline - 10\% & 46,8 & 30,9 & 31,8 & 53,9 & 42,5 & 37,1 \\
\hline NOVO IE MÉDIO & 52,0 & 33,8 & 34,4 & 58,9 & 47,6 & 41,3 \\
\hline Fck (MPa) & $\mathbf{3 4 , 8}$ & $\mathbf{2 2 , 7}$ & $\mathbf{2 3 , 1}$ & $\mathbf{3 9 , 4}$ & $\mathbf{3 1 , 9}$ & $\mathbf{2 7 , 7}$ \\
\hline
\end{tabular}

As medidas de resistência a compressão do concreto, obtidas nos ensaios, demonstram que em $67 \%$ dos pontos analisados, os valores do fck são superiores ao previsto em projeto (25 Mpa). Nos pontos E2 e E3 é possível observar que os valores obtidos nos ensaios de esclerometria são muito próximos aos estabelecidos em projeto.

\subsection{Determinação de Cloretos}

Os dados obtidos nas análises realizadas pelo método de Mohr foram inseridos na Tabela 3, com a indicação dos pesos utilizados, identificação das amostras, consumo de nitrato de prata na titulação das amostras e calculados os percentuais de cloreto em relação à massa de concreto e em relação a massa de cimento. 
Tabela 3- Resultado determinação de percentutal de cloreto

\begin{tabular}{|c|c|c|c|c|c|c|c|c|c|c|c|}
\hline \multirow{2}{*}{$\begin{array}{l}\text { Identificação } \\
\text { da Amostra }\end{array}$} & \multirow{2}{*}{$\begin{array}{l}\text { Profundidade } \\
\text { (cm) }\end{array}$} & \multirow{2}{*}{$\begin{array}{l}\text { Peso } \\
(\mathrm{g})\end{array}$} & \multicolumn{4}{|c|}{ AgNO3 (ml) Consumido } & \multirow{2}{*}{$\begin{array}{c}\mathrm{Cl}- \\
(\mathbf{m g / l})- \\
\text { Solução }\end{array}$} & \multirow{2}{*}{ Concreto(mg/l) } & \multirow{2}{*}{$\begin{array}{c}\text { Cimento } \\
(\mathrm{mg} / \mathrm{l})\end{array}$} & \multirow{2}{*}{$\begin{array}{c}(\%) \text { Cl- } \\
\text { relação } \\
\text { massa } \\
\text { concreto }\end{array}$} & \multirow{2}{*}{$\begin{array}{c}(\%) \text { Cl- } \\
\text { relação } \\
\text { massa } \\
\text { cimento }\end{array}$} \\
\hline & & & Branco & $1^{\text {a }}$ Tit. & $2^{\mathbf{a}}$ Tit. & Média & & & & & \\
\hline E1 & 0,50 & 0,514 & 1,30 & 1,90 & 1,90 & 1,90 & 3,00 & 2056 & 282,91 & 0,15 & 1,06 \\
\hline E1 & 1,00 & 0,532 & 0,70 & 1,00 & 1,01 & 1,01 & 1,53 & 2128 & 292,81 & 0,07 & 0,52 \\
\hline E1 & 1,50 & 0,502 & 0,70 & 0,80 & 0,60 & 0,70 & 0,00 & 2008 & 276,30 & 0,00 & 0,00 \\
\hline E1 & 2,00 & 0,529 & 0,70 & 0,70 & 0,70 & 0,70 & 0,00 & 2116 & 291,16 & 0,00 & 0,00 \\
\hline E2 & 0,50 & 0,515 & 1,30 & 1,70 & 1,80 & 1,75 & 2,25 & 2060 & 283,46 & 0,11 & 0,79 \\
\hline E2 & 1,00 & 0,520 & 1,30 & 2,00 & 1,50 & 1,75 & 2,25 & 2080 & 286,21 & 0,11 & 0,79 \\
\hline E2 & 1,50 & 0,512 & 1,30 & 1,50 & 1,60 & 1,55 & 1,25 & 2048 & 281,80 & 0,06 & 0,44 \\
\hline E3 & 0,50 & 0,514 & 1,30 & 1,60 & 2,40 & 2,00 & 3,50 & 2056 & 282,91 & 0,17 & 1,24 \\
\hline E3 & 1,00 & 0,516 & 1,30 & 1,50 & 1,60 & 1,55 & 1,25 & 2064 & 284,01 & 0,06 & 0,44 \\
\hline E3 & 1,50 & 0,510 & 1,30 & 1,40 & 1,50 & 1,45 & 0,75 & 2040 & 280,70 & 0,04 & 0,27 \\
\hline $\mathrm{F} 1$ & 0,50 & 0,509 & 1,30 & 1,80 & 1,90 & 1,85 & 2,75 & 2036 & 280,15 & 0,14 & 0,98 \\
\hline $\mathrm{F} 1$ & 1,00 & 0,511 & 1,30 & 1,30 & 1,40 & 1,35 & 0,25 & 2044 & 281,25 & 0,01 & 0,09 \\
\hline $\mathrm{F} 1$ & 1,50 & 0,507 & 1,30 & 1,40 & 1,30 & 1,35 & 0,25 & 2028 & 279,05 & 0,01 & 0,09 \\
\hline $\mathrm{F} 1$ & 2,00 & 0,512 & 1,30 & 1,40 & 1,30 & 1,35 & 0,25 & 2048 & 281,80 & 0,01 & 0,09 \\
\hline $\mathrm{F} 2$ & 0,50 & 0,516 & 1,30 & 1,35 & 1,50 & 1,43 & 0,63 & 2064 & 284,01 & 0,03 & 0,22 \\
\hline $\mathrm{F} 2$ & 1,00 & 0,507 & 1,30 & 1,30 & 1,30 & 1,30 & 0,00 & 2028 & 279,05 & 0,00 & 0,00 \\
\hline F2 & 1,50 & 0,508 & 1,30 & 1,30 & 1,30 & 1,30 & 0,00 & 2032 & 279,60 & 0,00 & 0,00 \\
\hline F3 & 0,50 & 0,513 & 1,30 & 1,90 & 1,80 & 1,85 & 2,75 & 2052 & 282,36 & 0,13 & 0,98 \\
\hline F3 & 1,00 & 0,504 & 1,30 & 1,60 & 1,60 & 1,60 & 1,50 & 2016 & 277,40 & 0,07 & 0,54 \\
\hline F3 & 1,50 & 0,512 & 1,30 & 1,30 & 1,35 & 1,33 & 0,13 & 2048 & 281,80 & 0,01 & 0,04 \\
\hline
\end{tabular}

A NBR 12655 (ABNT, 2015) apresenta uma tabela (Tabela 5) com recomendações para limites críticos de cloretos. Este percentual de cloretos é condicionado a classe de agressividade que a estrutura está inserida. Neste casao, a estrutura pertence as classes de agressividade III e IV : Concreto armado exposto à cloretos nas condições de serviço da estrutura, que determina como teor máximo de cloreto (CL-) em $0,15 \%$ sobre a massa de cimento

Nesta pesquisa, a concentração de cloretos está presente nos pontos mais próximos a superfície, a concentração de cloretos é superior ao valor tabela na referida norma em $60 \%$ dos pontos analisados, porém, à medida que se avança o furo o percentual de cloreto decresce.

Foi verificado que a profundidade de penetração de cloretos atinge no máximo 2,0 cm do cobrimento total, (onde foram obtidos $0,00 \%$ e $0,09 \%$ ) ou seja, na maior parte do cobrimento o concreto mantém-se em condições favoráveis à proteção da armadura, pois o a camada de cobrimento é de 4,0 cm (onde as barras de aço da armadura estão inseridas). 


\section{CONCLUSÃO}

Sabe-se que o pH do concreto, que em condições normais varia numa faixa de 11 a 13, é um dos fatores químicos mais importantes de proteção da armadura. Os resultados obtidos por meio do ensaio de carbonatação (solução de fenolftaleína a $1 \%$ ) apontam que a maior parte do cobrimento do concreto mantém-se alcalino.

A partir do ensaio de determinação de cloretos foi possível verificar que a penetração de cloretos atinge no máximo 2,0 $\mathrm{cm}$ do cobrimento total não atingindo a armadura que tem $4,0 \mathrm{~cm}$ de cobrimento como determina a NBR 6118 (ABNT, 2014) estando, portanto, condições favoráveis à proteção da armadura.

Referindo- se a resistência do concreto, considera-se que atende ao previsto, pois dos 6 pontos analisados, $67 \%$ dos pontos apresentaram resultados superiores ao Fck estabelecido no projeto estrutural (25 MPa). Ressalte-se ainda que os pontos localizados na zona não submersa apresentaram valores maiores de índices esclerométricos comparados aos demais pontos analisados.

É importante observar que, embora a ETE esteja a menos de 100 metros da linha de água, portanto clssificada como de muito forte agressividade pela NBR 6118 (ABNT, 2014) tem a proteção de outros prédios, está abaixo do nivel da rua e a direção dos ventos (nordeste) sopra afastando a névoa salina da estrutura.

Finalmente, este trabalho demonstra a importância de se fazer investigações técnicas no planejamento das intervenções de reparos estruturais.

\section{REFERÊNCIAS}

AMERICAN CONCRETE INSTITUTE. ACI 201.2R Guide to Durable Concrete: reported by ACI Committee 201. 2008. p. 1-53. Farmington Hills, Michigan, USA, 2008.

ANDRADE, J.J.O. et al. Avaliação das características do concreto quando submetido à degradação de origem química. In: Congresso Brasileiro do Concreto-REIBRAC, 45,2003, Vitória - ES. Anais. São Paulo: IBRACON, 2003.

ANDRADE, T.; SILVA, A.J.C. Patologia das Estruturas. In: ISAIA, Geraldo Cechella. (Ed) Concreto: In.: Concreto: Ensino, Pesquisa e Realizações. Editor: Geraldo Cechella Isaia. São Paulo: IBRACON, 2005, V.1, Cap. 32.

ASSOCIAÇÃO BRASILEIRA DE NORMAS TÉCNICAS. NBR 6118 (ABNET, 2014). Estrutura de concreto armado II. Rio de janeiro, 2014.

ASSOCIAÇÃO BRASILEIRA DE NORMAS TÉCNICAS. NBR 7584 (ABNT, 2012. Concreto endurecido - Avaliação da dureza superficial pelo esclerômetro de reflexão - Método de ensaio. Rio de janeiro, 2012.

ASSOCIAÇÃO BRASILEIRA DE NORMAS TÉCNICAS. NBR 12.655 (ABNT, 2015). Versão corrigida. Concreto de cimento Portland - Preparo, controle, recebimento e aceitação - Procedimento. Rio de Janeiro, 2015.

BERENGUER, R. et al. Verificação de penetração de cloretos em corpos de prova parcialmente imersos em água do mar em Recife, Pernambuco. Revista ALCONPAT, n. 8 (2), pp. 108 - 122, Recife, 2018.

BRANDÃO, A. M. da S.; PINHEIRO, L.M. Qualidade e durabilidade das estruturas de concreto armado: aspectos relativos ao projeto. Cadernos de Engenharia de Estruturas, n. 8, p. 1-25, São Carlos, 1999.

BRANDÃO, A. M. da S. Qualidade e durabilidade das estruturas de concreto armado: aspectos relativos ao projeto. 1998. 149f. Dissertação (Mestrado) - Escola de Engenharia de São Carlos, Universidade de São Paulo, São Carlos: 1998.

GONÇALVES, E. A. B. Estudo de patologias e suas causas nas estruturas de concreto armado de obras de edificações. 2015. 174 f. Monografia (Graduação) - Curso de Engenharia Civil, Universidade Federal do Rio de Janeiro, Rio de Janeiro, 2015.

HELENE, P. R. L. Manual para reparo, reforço e proteção de estrutura de concreto. 2 ed. São Paulo: Pini, 1992. 
HELENE, Paulo R. L. Manual de reabilitação de Estruturas de Concreto - Reparo, Reforço e Proteção. São Paulo: Red Rehabilitar, editores, 2003.

MAIA, G. F.; D’ÁVILA, C. A. Recuperação de estruturas de concreto no saneamento. Revista Concreto, São Paulo, v. 47, Jul-Set. 2007.

MEDEIROS, A.H.F, ANDRADE, J.J.O. HELENE, P. Durabilidade e vida útil das estruturas de concreto. In: Isaia, G.C.(Org.) 1. ed. Concreto: Ciência e Tecnologia. São Paulo: IBRACON, 2011, v.1, p.887-902.

PERDRIX, Maria del Carmen Andrade. Manual para Diagnóstico de Obras Deterioradas por Corrosão de Armaduras. Editora Pini, São Paulo, 1992.

PINHEIRO, L. M. Fundamentos do concreto e projeto de edifícios. São Carlos, maio de 2007. 24p.

RILEM - THE INTERNATIONAL UNION OF LABORATORIES AND EXPERTS IN CONSTRUCTION MATERIALS, SYSTEMS AND STRUCTURES. Measurement of hardened concrete carbonation depth Recommendations CPC-18. Mater. Struct., 21_126_, 453-455.1998.

SILVA, V. C. da. Patologias e recuperação de estruturas de concreto armado em ambientes sujeito a ataques de agentes externos. 2015. 62f. Monografia (Graduação) - Centro de Ciências Tecnológicas, Universidade de Fortaleza, Fortaleza, 2015.

SOUZA, V. C.; RIPPER, T. Patologia, recuperação e reforço de estruturas de concreto. São Paulo: Pini, 1998. 